\title{
Inertial picobalance reveals fast mass fluctuations in mammalian cells
}

David Martínez-Martín ${ }^{1 *}$, Gotthold Fläschner ${ }^{1 *}$, Benjamin Gaub $^{1}$, Sascha Martin $^{2}$, Richard Newton $^{1}$, Corina Beerli ${ }^{3}$, Jason Mercer ${ }^{3}$, Christoph Gerber ${ }^{2} \&$ Daniel J. Müller ${ }^{1}$

${ }^{1}$ Eidgenössische Technische Hochschule (ETH) Zürich, Department of Biosystems Science and Engineering, 4058 Basel, Switzerland.

${ }^{2}$ Swiss Nanoscience Institute (SNI), University of Basel, 4056 Basel, Switzerland.

${ }^{3}$ MRC Laboratory for Molecular Cell Biology, University College London, London WC1E 6BT, UK.

*These authors contributed equally to this work.

The regulation of size, volume and mass in living cells is physiologically important, and dysregulation of these parameters gives rise to many diseases ${ }^{1}$. Cell mass is largely determined by the amount of water, proteins, lipids, carbohydrates and nucleic acids present in a cell, and is tightly linked to metabolism, proliferation ${ }^{2}$ and gene expression ${ }^{3}$. Powerful technologies have emerged in recent years to track the mass of single suspended ${ }^{4,5}$ and adherent cells $^{6-8}$. However, it has not been possible to track individual adherent cells in physiological conditions at the mass and time resolutions required to observe fast cellular dynamics. Here, we introduce a picoscopic cell balance, based on an optically excited microresonator, that measures the total mass of single or multiple adherent cells in culture conditions over days with millisecond time resolution and picogram mass sensitivity. Using our technique, we observe that the mass of living mammalian cells fluctuates intrinsically by around one to four per cent over seconds throughout the cell cycle. Perturbation experiments link the mass fluctuations to the basic cellular processes of ATP synthesis and water transport. Furthermore, we show that growth and cell cycle progression are arrested in cells infected with vaccinia virus, but mass fluctuations continue until cell death. Our measurements suggest that all living cells show fast and subtle mass fluctuations throughout the cell cycle. As our cell balance is easy to handle and compatible with fluorescence microscopy, we anticipate that our nanotechnological approach will contribute to the understanding of cell mass regulation in various cell states and across time scales, which is of great 


\section{importance in areas including physiology, cancer research, stem cell differentiation and drug discovery.}

Flow cytometers or Coulter devices are among the most commonly used technologies to characterize the size and volume of suspended cells ${ }^{9}$. These devices are usually used to study a large distribution of cells, as they cannot monitor single cells with great accuracy. Furthermore, these technologies are not suitable to study the mechanisms that guide cell growth and volume ${ }^{10}$, as the cell cycles of most cells are not synchronized. Cell volume and mass are tightly linked and thus a number of highly promising approaches have been introduced to detect the mass of single cells, including microchannel resonators ${ }^{11}$ and pedestal mass sensors ${ }^{7}$. Microchannel resonators measure the buoyant mass of suspended cells at sub-femtogram accuracy ${ }^{11}$. The buoyant mass is the total mass of the cell minus that of the fluid displaced by the cell. By measuring the buoyant cell mass in two fluids of different density, which takes around $1-15 \mathrm{~s}$, the total cell mass can be extrapolated ${ }^{12}$. Such extrapolation assumes that the cell does not change in volume over the time course of the measurement or upon exposure to different fluids. In addition, most mammalian cells adhere to surfaces and behave considerably differently if suspended. Thus, ideally one should characterize the total mass of adherent cells in the physiologically relevant state $^{13}$ and at millisecond time resolution to capture the dynamic nature of cellular processes. Pedestal mass sensors can measure the total mass of adherent cells with an accuracy of $8.5 \mathrm{pg}$ and a time resolution of around $1 \mathrm{~min}^{7}$. However, this method approximates the mass of a living cell by using the chemically fixed cell as a mass reference. This approximation assumes that the cell does not change in volume or mass during chemical fixation, which has been a matter of debate for decades ${ }^{14-16}$. Moreover, neither state-of-the-art technique allows time-lapse mass measurements to be recorded while simultaneously conducting fluorescence and/or differential interference contrast microscopy in order to link cell mass dynamics to cell morphology and state. In summary, there is currently no method that can detect the state and mass of single adherent cells over a time range (from milliseconds to days) and at a mass resolution (below 1\% ${ }^{10}$ sufficient to characterize how cells regulate mass and volume.

Here, we introduce a picoscopic cell balance that can be used to noninvasively measure adherent cells at high mass and time resolution. The balance, 
which is based on an actively actuated silicon microcantilever, is mounted on an inverted optical microscope and operates under cell culture conditions ${ }^{17}$ (Fig. 1a). Attaching a cell to the microcantilever changes the effective mass and thus shifts the natural resonance frequency of the cantilever. However, accurately detecting the natural resonance frequency of a non-driven cantilever in liquid is difficult. To enhance the mass sensitivity of the cantilever, a low-power intensity-modulated blue laser $(405 \mathrm{~nm}, \leq 50 \mu \mathrm{W})$ is focused at the base of the cantilever to generate very small cantilever oscillations in the range of approximately 1-15 $\AA$ (Fig. 1b). To avoid interference with the blue laser, the adhering cell is placed at the opposite end of the cantilever. The movement, amplitude and phase of the cantilever (Fig. 1b) are read out optically by an infrared laser $(852 \mathrm{~nm}, \leq 250 \mu \mathrm{W})$. These values are perfectly fitted by a driven and damped harmonic oscillator model, making the mass analysis of the attached cell straightforward (Fig. 1c and Supplementary Notes 1,2). The phase, which represents the delay between the signal activating the cantilever and its mechanical response, is $90^{\circ}$ at the natural resonance frequency $f_{\mathrm{N}}$ of the cantilever (Fig. 1c). This frequency can be written as $f_{\mathrm{N}}=(2) \sqrt[1]{k / m^{*}}$, where $m^{*}$ is the effective mass and $k$ the spring constant of the cantilever ${ }^{18}$. Thus, by measuring the natural resonance frequency $f_{\mathrm{N}}$ of the cantilever before and after attaching a cell, the cell mass can be determined. To precisely $\operatorname{link} f_{\mathrm{N}}$ to the cell mass requires localization of the added mass on the cantilever, which can be achieved optically (Supplementary Note 3). The error at which the total mass of the cell can be determined is therefore related to the resolution limit of the optical microscope (Supplementary Note 4). As a control, we recorded phase curves of a cantilever in cell culture medium with and without balancing weights placed at different locations along the length of the cantilever (Fig. 1d, e; Extended Data Fig. 1). The weights were silicon blocks milled with a focused ion beam (FIB) and their volume and mass (ranging from 0.82 to $1.74 \mathrm{ng}$ ) were determined by scanning electron microscopy (SEM). A comparison of the mass estimated via SEM and measured by the balance matched to within the error of SEM estimation (approximately $8 \%$ ). We could thus validate the physical principle of our cell balance.

Following the proof of principle, we used our technology to measure the mass of adherent mammalian cells. To monitor the cell mass over many hours or days, we developed a controlled environmental system that provides cell culture conditions by 
avoiding water evaporation of the culture medium and supplying humidified air with 5\% $\mathrm{CO}_{2}$ under sterile conditions (Fig. 1a; Extended Data Fig. 2). The system maintains a constant temperature of $37.0 \pm 0.1^{\circ} \mathrm{C}$, thus avoiding thermal drift of the mass measurement (Fig. 1f). To achieve high temporal resolution of $10 \mathrm{~ms}$ and instantaneously follow the natural resonance frequency shifts of the cantilever, we used a phase-locked loop as feedback system. With this setup, the noise level or mass resolution approached approximately $5 \mathrm{pg}$. However, this noise level of the mass measurements depends on the material, dimension, and oscillation amplitude of the cantilever ${ }^{19}$ as well as on the bandwidth (that is, the temporal resolution) of the measurement ${ }^{18}$ (Supplementary Note 1$)$.

As a first biological application of our balance, we characterized the mass of adherent mammalian cells in the interphase (Fig. 2). We chose mouse fibroblasts and HeLa cells (a human cancer-derived cell line), as they are frequently studied in cell biology. To facilitate the attachment of fibroblasts and HeLa cells to the microcantilever, we functionalized the cantilever surface with the extracellular matrix proteins fibronectin and collagen type I, respectively ${ }^{20-22}$. The motorized stage of the optical microscope was then used to position the functionalized cantilever over a freshly trypsinized cell onto which the flat cantilever was gently pushed (with a force of $1-5 \mathrm{nN}$ ) into contact. Once in contact with the cantilever, cells adhered quickly. Following the attachment of the cell, the cantilever was retracted to at least $150 \mu \mathrm{m}$ from the culture dish, to avoid any further interactions of the cell-cantilever system with the cell culture dish. Because cell mass, morphology and state are tightly linked, we simultaneously recorded differential interference contrast (DIC) and/or fluorescence images of mouse fibroblasts and HeLa cells stably expressing enhanced green fluorescent protein (eGFP)-labelled histone (H2B-eGFP) and mCherry-labelled actin (mCherry-actin) (Fig. 2a). Five minutes after retraction, the mass of the adhering fibroblast or HeLa cell was measured (Fig. 2b). On average, single HeLa cells and mouse fibroblasts had masses of $2.43 \mathrm{ng}$ and $2.29 \mathrm{ng}$, respectively. Next, we determined the average cell volume for each cell line using a Coulter device (Fig. 2b). Cell mass and volume were then used to determine the density of $1.05 \pm 0.08 \mathrm{~g} \mathrm{ml}^{-1}$ (mean \pm s.e., $n=24$ ) for HeLa cells and $1.13 \pm 0.10 \mathrm{~g} \mathrm{ml}^{-1}(n=24)$ for mouse fibroblasts, which are in good agreement with the values of $1.04-1.08 \mathrm{~g} \mathrm{ml}^{-1}$ published previously ${ }^{23}$. Next, we monitored the mass of single interphase fibroblasts 
and HeLa cells at a high temporal resolution of $10 \mathrm{~ms}$. Both cell types showed dynamic mass fluctuations in the range of seconds (Fig. 2c, d). Analysis of these fluctuations revealed fast (approximately $2 \mathrm{~s}$ ) and slow (approximately $18 \mathrm{~s}$ ) components with amplitudes of around 12-15 pg (Extended Data Fig. 3). Optical monitoring of cell morphology and state revealed no displacement of the cells or their nuclei on the cantilever during mass measurements (Extended Data Fig. 4a-c). We could thus exclude the possibility that changes in the cell position on the cantilever caused the mass fluctuations. Positional displacements of the cell below the resolution limit of our optical microscope were discounted as a source of cell mass fluctuations as they would not cause sufficient mass changes (Supplementary Note 4). Furthermore, rounded cells that were unable to change position on the cantilever fluctuated in mass similarly to adherent cells (Extended Data Fig. 4c-e). We also sculpted L-shaped microcantilevers to monitor the mass of adherent cells independent of cellular movements (Fig. 3). Cells adhering to the plate at the free end of the cantilever could move perpendicular to but not along the cantilever. These cells also showed fast and slow mass fluctuations that were indistinguishable from those detected with normal microcantilevers. We further investigated whether the adherent state or contraction of a cell influenced the mass measurements, which they did not (Extended Data Figs 5, 6). Finally, the mass fluctuations ceased when we fixed the cells using glutaraldehyde (Fig. 2c), suggesting that the fluctuations are intrinsic to living cells.

To investigate possible links between cell mass fluctuations and function, we used our picobalance to assay chemical perturbations of HeLa cells (Extended Data Fig. 7 and Table 1). As the mass fluctuations involve around $1-4 \%$ of the total cell mass, they could originate from the exchange of intracellular water. We therefore decided to perturb water transport across the cell membrane by blocking aquaporins with $\mathrm{HgCl}_{2}$, which considerably reduced the amplitude of slow mass fluctuations by a factor of about 4 from approximately $14 \mathrm{pg}$ to approximately $4 \mathrm{pg}$, while the fast mass fluctuations reduced from approximately $15 \mathrm{pg}$ to approximately $11 \mathrm{pg}$. Further, we thought that the exchange of water could be driven by cell energy-related processes. We therefore perturbed cellular metabolism by preventing glycolysis or by depolarizing mitochondria and the cellular energy supply by inhibiting ATP synthase. Depolarization of mitochondria with 2,4-dinitrophenol, prevention of glycolysis by 
starving the cells in glucose-free medium, or inhibition of ATP synthesis using oligomycin A did not substantially affect the cell mass fluctuations. However, inhibition of ATP synthesis in starved cells reduced the slow mass fluctuations to around $3 \mathrm{pg}$ and the fast mass fluctuations to around $10 \mathrm{pg}$ - similar levels to those seen when water transport was inhibited. These experiments showed that the mass fluctuations of mammalian cells depend on cellular energy and water exchange, thus linking basic physiological functions to the mass phenomena observed.

We also tested whether our approach could be used to investigate how viral infection affects cell mass over time. The cytopathic effect - changes in cell size and mass, shape and physiology linked to pathogen infection - was first described in the $1950 \mathrm{~s}^{24}$. This effect is widely investigated and is used as a marker of clinical infection and as a readout for large-scale anti-viral development, and more recently has been linked to innate immune responses ${ }^{25,26}$. Nonetheless, beyond visual hallmarks, little is known about the impact pathogens have on cell size and mass. Intuitively one would assume that the mass of a virus-infected cell would increase over time as a result of the production of virus particles. To our knowledge, no single cell analysis of the effect of viral infection on cell mass has been performed. Therefore, we decided to investigate the mass of vaccinia virus (VACV)-infected HeLa cells. In order to monitor cell growth over the infectious cycle, we developed an approach to infect single cells in a spatially and temporally controlled fashion. By attaching a single HeLa cell to the cantilever and bringing it into mechanical contact with a cell infected with VACV, we could transfer the virus to the uninfected HeLa cell (Fig. 4a, b and Methods). This directed single-cell infection approach mimics the natural mechanism by which VACV spreads from cell to cell ${ }^{27}$ and allowed us to monitor cell mass from the onset of viral infection. A recombinant VACV that packages eGFP-tagged structural proteins used for these experiments allowed us to follow the production of new virus particles by fluorescence microscopy. After around $4-5 \mathrm{~h}$ of incubation, the eGFP signal could be detected in the infected HeLa cell. The fluorescence intensity increased over time, indicating that the infected cell was producing new VACV (Fig. 4c). Measuring the mass of virus-infected HeLa cells at high time resolution revealed fluctuations similar to those observed for uninfected HeLa cells (Fig. 4d and Extended Data Fig. 8). Unexpectedly, when VACV-infected HeLa cells were monitored over longer time frames (even up to $40 \mathrm{~h}$ ) we measured largely constant mass despite the 
production of new viruses (Fig. 4e and Extended Data Fig. 9). In comparison, uninfected HeLa cells grown for similar times continuously increased in mass. These results demonstrate a considerable difference in growth behaviour between uninfected and VACV-infected HeLa cells that could be detected only using the cell balance. Notably, VACV infection has been shown to arrest cell cycle progression ${ }^{28}$ and halt proliferation by shifting cells to S-phase ${ }^{29}$. While the mechanisms used by VACV to achieve this remain unclear, it is noteworthy that cell cycle progression is generally halted in mammalian cells that do not undergo sufficient growth to reach a mass threshold ${ }^{30}$.

The ability to measure the mass of single or small numbers of mammalian adherent cells offers opportunities to explore how individual cells or those within tissue control mass during basic processes such as cell shape changes, migration, growth, differentiation or disease. The examples in our study provide unexpected insights into cell mass regulation. Living mouse fibroblasts, HeLa cells and VACVinfected HeLa cells undergo quick mass fluctuations on the picogram scale in the range of seconds, whereas dead cells do not. As these mass fluctuations occur regardless of the cell state, one might speculate that they are universal to mammalian cells. In a first attempt to investigate the origin of these fluctuations we link them to basic cellular processes such as ATP synthesis and glycolysis and to water transport across the cell membrane. In addition, our technique for direct transmission of viruses by mechanical contact between cells provides an opportunity to study the mechanisms of virus transfer ${ }^{31}$. We also found that VACV-infected cells stop growing while producing viruses. Halting cell growth also interferes with other mechanisms of cell cycle progression, including mitosis ${ }^{30}$. Perhaps this mechanism is used by other viruses as well to modulate the host cell cycle to their advantage. We envision that, owing to its simplicity and compatibility with optical microscopy, the picoscopic cell balance will become an important tool for investigation of how cells regulate mass in many cell states, for use in biophysics, cell biology, physiology and medicine. Our initial efforts to link basic cellular processes to cell mass regulation exemplify how the picobalance could be applied in the future.

Received 16 November 2016; accepted 12 September 2017.

$<$ jrn>1. Lloyd, A. C. The regulation of cell size. Cell 154, 1194-1205 (2013).

$\underline{\text { Medline }} \underline{\text { CrossRef }}</$ jrn $>$ 
$<\mathrm{jrn}>2$. Lang, F. et al. Functional significance of cell volume regulatory mechanisms. Physiol. Rev. 78, 247-306 (1998). Medline</jrn>

$<\mathrm{jrn}>3$. Häussinger, D. The role of cellular hydration in the regulation of cell function. Biochem. J. 313, 697-710 (1996). Medline $\underline{\text { CrossRef }</ j r n>}$

$<\mathrm{jrn}>4$. Cermak, N. et al. High-throughput measurement of single-cell growth rates using serial microfluidic mass sensor arrays. Nat. Biotechnol. 34, 1052-1059 (2016). Medline CrossRef $</$ jrn $>$

$<\mathrm{jrn}>5$. Stevens, M. M. et al. Drug sensitivity of single cancer cells is predicted by changes in mass accumulation rate. Nat. Biotechnol. 34, 1161-1167 (2016). $\underline{\text { Medline }} \underline{\text { CrossRef }}</$ jrn $>$

<jrn>6. Zlotek-Zlotkiewicz, E., Monnier, S., Cappello, G., Le Berre, M. \& Piel, M. Optical volume and mass measurements show that mammalian cells swell during mitosis. J. Cell Biol. 211, 765-774 (2015). Medline CrossRef $<$ jrn>

$<$ jrn>7. Park, K. et al. Measurement of adherent cell mass and growth. Proc. Natl Acad. Sci. USA 107, 20691-20696 (2010). Medline CrossRef $</$ jrn $>$

$<\mathrm{jrn}>8$. Bottier, C. et al. Dynamic measurement of the height and volume of migrating cells by a novel fluorescence microscopy technique. Lab Chip 11, 3855-3863 (2011). Medline $\underline{\text { CrossRef }</ j r n>}$

$<$ jrn $>9$. Robinson, J. P. \& Roederer, M. Flow cytometry strikes gold. Science 350, 739-740 (2015). Medline $\underline{\text { CrossRef }</ j r n>}$

$<$ jrn $>10$. Zangle, T. A. \& Teitell, M. A. Live-cell mass profiling: an emerging approach in quantitative biophysics. Nat. Methods 11, 1221-1228 (2014). $\underline{\text { Medline CrossRef }</ j \mathrm{jn}>}$

$<$ jrn $>11$. Burg, T. P. et al. Weighing of biomolecules, single cells and single nanoparticles in fluid. Nature 446, 1066-1069 (2007). Medline $\underline{\text { CrossRef }}</$ jrn $>$

$<\mathrm{jrn}>12$. Bryan, A. K. et al. Measuring single cell mass, volume, and density with dual suspended microchannel resonators. Lab Chip 14, 569-576 (2014). $\underline{\text { Medline }} \underline{\text { CrossRef }}</$ jrn $>$ 
$<$ jrn $>$ 13. Schroeder, T. Long-term single-cell imaging of mammalian stem cells. Nat. Methods 8 (Suppl.), S30-S35 (2011). Medline CrossRef $</$ jrn $>$

$<$ jrn $>14$. Eisenberg, B. R. \& Mobley, B. A. Size changes in single muscle fibers during fixation and embedding. Tissue Cell 7, 383-387 (1975). Medline CrossRef $</$ jrn $>$

$<\mathrm{jrn}>15$. Li, Z. et al. MRT letter: application of novel "in vivo cryotechnique" in living animal kidneys. Microsc. Res. Tech. 76, 113-120 (2013). Medline $\underline{\text { CrossRef }}</$ jrn $>$

$<$ unknown $>16 . \quad$ Kellenberger, E. The potential of cryofixation and freeze substitution - observations and theoretical considerations. J. Microsc. 161, 183-203 (1991).</unknown>

$<\mathrm{jrn}>17$. Alsteens, D. et al. Nanomechanical mapping of first binding steps of a virus to animal cells. Nat. Nanotechnol. 12, 177-183 (2017). Medline $\underline{\text { CrossRef }}</$ jrn $>$

$<$ bok>18. Sarid, D. Scanning Force Microscopy: With Applications to Electric, Magnetic, and Atomic Forces (Oxford Univ. Press, 1991). $</$ bok $>$

<jrn>19. Albrecht, T. R., Grutter, P., Horne, D. \& Rugar, D. Frequencymodulation detection using high-Q cantilevers for enhanced force microscope sensitivity. J. Appl. Phys. 69, 668-673 (1991). CrossRef $</ \mathrm{jrn}>$

$<$ jrn $>20$. Friedrichs, J., Helenius, J. \& Müller, D. J. Stimulated single-cell force spectroscopy to quantify cell adhesion receptor crosstalk. Proteomics $\mathbf{1 0}$, 1455-1462 (2010). Medline CrossRef $<$ jrn $>$

$<$ jrn $>21 . \quad$ Friedrichs, J., Helenius, J. \& Muller, D. J. Quantifying cellular adhesion to extracellular matrix components by single-cell force spectroscopy. Nat. Protocols 5, 1353-1361 (2010). $\underline{\text { Medline }} \underline{\text { CrossRef }</ j r n>}$

$<$ jrn>22. Helenius, J., Heisenberg, C. P., Gaub, H. E. \& Muller, D. J. Single-cell force spectroscopy. J. Cell Sci. 121, 1785-1791 (2008). Medline CrossRef $</$ jrn $>$

$<\mathrm{edb}>23$. Pertoft, H. \& Laurent, T. C. in Methods of Cell Separation (ed. Catsimpoolas, N.) 25-65 (Springer, 1977).</edb $>$ 
$<$ jrn $>24$. Wright, J. Cytopathic effect on primate and rodent tissue-cultures of agent isolated from measles patient. Lancet 272, 669-670 (1957).

$\underline{\text { Medline }}</$ jrn $>$

$<\mathrm{jrn}>25$. Monel, B. et al. Zika virus induces massive cytoplasmic vacuolization and paraptosis-like death in infected cells. EMBO J. 36, 1653-1668 (2017). $\underline{\text { Medline }} \underline{\text { CrossRef }</ \text { jrn }>}$

$<$ jrn>26. Stanton, R. J. et al. HCMV pUL135 remodels the actin cytoskeleton to impair immune recognition of infected cells. Cell Host Microbe 16, 201-214 (2014). Medline $\underline{\text { CrossRef }</ j r n>}$

$<\mathrm{jrn}>27$. Blasco, R. \& Moss, B. Role of cell-associated enveloped vaccinia virus in cell-to-cell spread. J. Virol. 66, 4170-4179 (1992). Medline $</$ jrn $>$

$<$ jrn $>28$. Wali, A. \& Strayer, D. S. Infection with vaccinia virus alters regulation of cell cycle progression. DNA Cell Biol. 18, 837-843 (1999). Medline CrossRef $</$ jrn $>$

$<$ jrn $>29$. Kit, S. \& Dubbs, D. R. Biochemistry of vaccinia-infected mouse fibroblasts (strain L-M). I. Effects on nucleic acid and protein synthesis. Virology 18, 274-285 (1962). Medline CrossRef $</$ jrn $>$

$<$ jrn>30. Conlon, I. \& Raff, M. Size control in animal development. Cell 96, 235-244 (1999). Medline CrossRef $</$ jrn $>$

$<$ jrn $>31 . \quad$ Sattentau, Q. Avoiding the void: cell-to-cell spread of human viruses. Nat. Rev. Microbiol. 6, 815-826 (2008). Medline CrossRef $</$ jrn $>$

Supplementary Information is available in the online version of the paper.

Acknowledgements We thank H.-P. Lang, F. Huber, W. Junge, E. Meyer, T. Glatzel and J. Adams for discussion; E. Meyer, T. Glatzel and A. Tonin for help with the beam deflection diagram; the mechanical and electronic workshops of the Physics Department of University Basel, P. Buchmann and P. Argast for help with building our device; A. Ponti for technical support with Imaris 8.1 to determine cell position; D. Mathys for assisting with electron microscopy and focused ion beam lithography; T. Lopez and V. Jäggin for assistance with FACS operation; and Newport Corporation, Attocube Systems AG, Nanonis (SPECS Zurich GmbH), Carl Zeiss AG and Nanosurf AG for technical support. This work was funded by the Swiss Commission for Technology and Innovation (CTI; grant 17970.1 PFNM-NM to D.J.M.), the European Molecular Biology Organization (EMBO; ALTF 506-2012 to D.M.-M. and ALTF 424-2016 to B.G.), the Swiss Nanoscience Institute Basel and the NCCR 
Molecular Systems Engineering. C.B. and J.M. are supported by core funding to the MRC Laboratory for Molecular Cell Biology, University College London.

Author Contributions D.M.-M., G.F., C.G. and D.J.M. designed the experiments. D.M.-M., C.G., S.M. and D.J.M. designed and built the cell balance. R.N. generated the fibroblast cell line stably expressing H2B-eGFP and mCherry-actin. D.M.-M. and G.F. set up the controlled environmental system and conducted all experiments. B.G. performed parts of the VACV experiments. D.M.-M., G.F., C.G. and D.J.M analysed the data. C.B. and J.M. constructed, produced and purified the VACV and provided the HeLa (ATCC CCL-2) and BSC40 (ATCC CRL-2761) cell lines. D.M.-M., G.F., B.G., R.N., J.M., C.G. and D.J.M. wrote the manuscript. All authors discussed the experiments, read and approved the manuscript.

Author Information Reprints and permissions information is available at www.nature.com/reprints. The authors declare competing financial interests: details are available in the online version of the paper. Readers are welcome to comment on the online version of the paper. Publisher's note: Springer Nature remains neutral with regard to jurisdictional claims in published maps and institutional affiliations. Correspondence and requests for materials should be addressed to D.M.-M. (david.martinez@bsse.ethz.ch)or D.J.M. (daniel.mueller@bsse.ethz.ch).

Reviewer Information Nature thanks Y. Dufrene, G. Wuite and the other anonymous reviewer(s) for their contribution to the peer review of this work.

Table 1 | Mass fluctuations in HeLa cells depend on ATP synthesis and water transport

\begin{tabular}{|c|c|c|c|c|c|}
\hline \multirow{2}{*}{$\begin{array}{l}\text { Experimental } \\
\text { conditions }\end{array}$} & \multirow[t]{2}{*}{ Action } & \multicolumn{2}{|l|}{ Periods (s) } & \multicolumn{2}{|c|}{ Amplitude (pg) } \\
\hline & & Slow & Fast & Slow & Fast \\
\hline $\begin{array}{l}\text { Untreated HeLa } \\
\text { cells (control) }\end{array}$ & & $\begin{array}{l}18.0 \pm 1.4 \\
(n=17)\end{array}$ & $\begin{array}{l}2.1 \pm 0.1 \\
(n=177)\end{array}$ & $\begin{array}{l}14 \pm 2 \\
(n=17)\end{array}$ & $\begin{array}{l}15 \pm 1 \\
(n=177)\end{array}$ \\
\hline $\begin{array}{l}2,4- \\
\text { dinitrophenol } \\
(0.4 \mathrm{mM})\end{array}$ & $\begin{array}{l}\text { Depolarizes } \\
\text { mitochondria }\end{array}$ & $\begin{array}{l}19.9 \pm 2.9^{\mathrm{NS}} \\
\mathrm{Cl}(-8.0 \\
4.2) \\
(n=12)\end{array}$ & $\begin{array}{l}2.1 \pm 0.1^{\mathrm{NS}} \\
\mathrm{Cl}(-0.2 \\
0.2) \\
(n=150)\end{array}$ & $\begin{array}{l}16 \pm 4^{\mathrm{NS}} \\
\mathrm{CI}(-10.7 \\
5.1) \\
(n=12)\end{array}$ & $\begin{array}{l}14 \pm 1^{*} \\
\mathrm{Cl}(0.4,3.4) \\
(n=150)\end{array}$ \\
\hline $\begin{array}{l}\text { Oligomycin A } \\
(10 \mu \mathrm{M})\end{array}$ & $\begin{array}{l}\text { Inhibits ATP } \\
\text { synthase }\end{array}$ & $\begin{array}{l}15.4 \pm 1.4^{\mathrm{NS}} \\
\mathrm{Cl}(-1.2 \\
7.1) \\
(n=14)\end{array}$ & $\begin{array}{l}2.1 \pm 0.1^{\mathrm{NS}} \\
\mathrm{Cl}(-0.2 \\
0.3) \\
(n=113)\end{array}$ & $\begin{array}{l}14 \pm 2^{\mathrm{NS}} \\
\mathrm{Cl}(-6.8 \\
6.9) \\
(n=14)\end{array}$ & $\begin{array}{l}14 \pm 1^{*} \\
\mathrm{Cl}(0.1,3.2) \\
(n=113)\end{array}$ \\
\hline Glucose-free & $\begin{array}{l}\text { Prevents } \\
\text { glycolysis }\end{array}$ & $\begin{array}{l}16.7 \pm 1.2^{\mathrm{NS}} \\
\mathrm{Cl}(-2.7 \\
5.3) \\
(n=12)\end{array}$ & $\begin{array}{l}1.8 \pm 0.1^{\mathrm{NS}} \\
\mathrm{Cl}(-0.1 \\
0.8) \\
(n=127)\end{array}$ & $\begin{array}{l}14 \pm 3^{\mathrm{NS}} \\
\mathrm{Cl}(-6.3 \\
6.3) \\
(n=12)\end{array}$ & $\begin{array}{l}16 \pm 1^{\mathrm{NS}} \\
\mathrm{Cl}(-0.7 \\
2.4) \\
(n=127)\end{array}$ \\
\hline $\begin{array}{l}\text { Oligomycin A } \\
(10 \mu \mathrm{M})+ \\
\text { glucose-free }\end{array}$ & $\begin{array}{l}\text { Inhibits ATP } \\
\text { synthase } \\
\text { and prevents } \\
\text { glycolysis }\end{array}$ & $\begin{array}{l}14.0 \pm 1.5^{\star} \\
\mathrm{Cl}(0.8,8.4) \\
(n=14)\end{array}$ & $\begin{array}{l}1.8 \pm 0.1^{*} \\
\mathrm{Cl}(0.1,0.5) \\
(n=129)\end{array}$ & $\begin{array}{l}3 \pm 1^{* * * *} \\
\mathrm{CI}(6.5 \\
16.9) \\
(n=14)\end{array}$ & $\begin{array}{l}10 \pm 1^{* * * *} \\
\mathrm{Cl}(3.9,6.6) \\
(n=129)\end{array}$ \\
\hline $\begin{array}{l}\text { Mercury(II) } \\
\text { chloride } \\
(200 \mu \mathrm{M})\end{array}$ & $\begin{array}{l}\text { Blocks } \\
\text { aquaporins }\end{array}$ & $\begin{array}{l}17.4 \pm 2.3^{\mathrm{NS}} \\
\mathrm{Cl}(-4.4 \\
5.5) \\
(n=11)\end{array}$ & $\begin{array}{l}1.9 \pm 0.1^{\mathrm{NS}} \\
\mathrm{Cl}(-0.1 \\
0.4) \\
(n=122)\end{array}$ & $\begin{array}{l}4 \pm 1^{* \star *} \\
\mathrm{CI}(4.1 \\
16.4) \\
(n=11)\end{array}$ & $\begin{array}{l}11 \pm 1^{* * * *} \\
\mathrm{Cl}(2.7,5.6) \\
(n=122)\end{array}$ \\
\hline
\end{tabular}


Periods and amplitudes of cell mass fluctuations measured for untreated HeLa cells (control) and perturbed HeLa cells under the same conditions as in Extended Data Fig. 7. To evaluate the statistical significance of possible differences, every data set was compared to the control data set using the two-sided student's $t$-test. NS, not significant $(P>0.05)$; ${ }^{*} \leq 0.05$; ${ }^{* *} P \leq 0.01 ;{ }^{* * *} P \leq 0.001 ;{ }^{* * * *} P \leq 0.0001$. Cl, $95 \%$ confidence interval for the difference between the control and test mean, that is, the confidence interval for the $t$-test's null hypothesis. $n$ is the number of fluctuations analysed from at least three biologically independent cells.

[Author: Please ensure that the following information is included in the figure legends where relevant. Sample size (exact $n$ number); a statement of replicability (how many times was experiment replicated in the laboratory); description of sample collection (clarify whether technical or biological replicates and include how many animals, litters, cultures, etc.); state the statistical test used and give $P$ values; define centre values (median or average) and error bars. For figures/images that are reproduced or adapted from a third party, it is important that you confirm that permission has been obtained and that appropriate acknowledgement of the copyright holder is given.]

Figure 1 | Working principle of the picoscopic cell balance in culture conditions.

a, Design of the cell balance. The chamber surrounding the microcantilever used to pick up and measure the mass of an adherent cell controls temperature, gas atmosphere and humidity to prevent evaporation of the culture medium (Methods). Sliding lids allow the microcantilever holder to be moved relative to the Petri dish. The chamber is compatible with optical microscopy. $\mathbf{b}$, The mass of a cell adhering to the cantilever is measured by oscillating the cantilever at its natural resonance frequency $f_{\mathrm{N}}$ and amplitudes of around 1-15 $\AA$ using an intensity-modulated blue laser at its base. Oscillation amplitude and frequency are read out by reflecting an infrared laser from the free end of the cantilever. Simultaneously, cell morphology and state are characterized by optical microscopy. c, Typical cantilever amplitude (green) and phase (red) response measured in cell culture medium. A driven and damped harmonic oscillator model fits (thin lines) the experimental data. $f_{\mathrm{N}}$ is the cantilever frequency at a phase of $90^{\circ}$. d, SEM images of a cantilever with and without a weight at the end. The weight $\left(11.6 \times 25.8 \times 2.5 \mu \mathrm{m}^{3}\right)$ is made of silicon $\left(2.33 \mathrm{~g} \mathrm{~cm}^{-3}\right)$ and has a mass of $1.74 \pm 0.23 \mathrm{ng}$. Scale bars, $15 \mu \mathrm{m}$ (left); $5 \mu \mathrm{m}$ (right). e, Phase curves of the cantilever with and without the balancing weight (as in c) measured in culture medium. The shift of $f_{\mathrm{N}}$ by $8.451 \mathrm{kHz}$ corresponds to a mass of $1.61 \mathrm{ng}$. $\mathbf{f}$, Noise of the $f_{\mathrm{N}}$ of a cantilever in culture medium. Data recorded over $2 \mathrm{~h}$ show the stability of the balance and its sensitivity in the picogram $\left(10^{-12} \mathrm{~g}\right)$ range. 
Figure 2 | Mass fluctuations of single adherent animal cells in interphase. a, DIC and fluorescent images of a rounded interphase fibroblast attached to a collagencoated microcantilever. H2B-eGFP (green) and mCherry-actin (red) are visualized. Scale bar, $20 \mu \mathrm{m}$. b, Left, interphase cell mass measured for single HeLa cells and fibroblasts (fibrobl.) (left). Each dot corresponds to the mass of a single cell. The average mass (grey lines) of HeLa cells was $2.43 \pm 0.19 \mathrm{ng}$ (mean \pm s.e.; $n=24)$ and of fibroblasts was $2.29 \pm 0.19 \mathrm{ng}(n=24)$. Right, volume distribution of interphase HeLa cells and fibroblasts as acquired with a Coulter device. Volumes of $2,310 \pm 55 \mu^{3}$ (mean \pm s.e.; $\left.n=606\right)$ and 2,003 $\pm 59 \mu \mathrm{m}^{3}(n=612)$ were obtained for HeLa cells and fibroblasts, respectively. $n$ is the number of biologically independent cells. Measurements were repeated at least three times. c, d, Masses of three fibroblasts (c) and three HeLa cells (d) monitored at 10-ms time resolution (black lines). Fibroblasts experience fast mass fluctuations (red lines; period $2.2 \pm 0.1 \mathrm{~s}$; amplitude $14 \pm 1 \mathrm{pg}($ mean \pm s.e.; $n=132))$ and slow mass fluctuations (green lines; period $17.6 \pm 2.0 \mathrm{~s}$; amplitude $12 \pm 1 \mathrm{pg}(n=10)$ ). HeLa cells experience fast mass fluctuations (period $2.1 \pm 0.1 \mathrm{~s}$; amplitude $15 \pm 1 \mathrm{pg}(n=177)$ ) and slow mass fluctuations (period $18.0 \pm 1.4 \mathrm{~s}$; amplitude $14 \pm 2 \mathrm{pg}(n=17)$ ). $n$ is the number of fluctuations analysed from at least three biologically independent cells. For details of analysis see Extended Data Fig. 3. The first graph in $\mathbf{c}$ also shows the mass over time of a chemically fixed fibroblast (grey line), which has been offset to facilitate comparison.

Figure 3 | Cell mass fluctuations measured using a position-insensitive L-shaped microcantilever. a, b, SEM images showing perspective and side views of an Lshaped microcantilever, sculpted with an FIB. c, Schematic showing how a cell is attached to the plate of the L-shaped microcantilever. The cantilever is moved laterally towards the cell in order to attach the cell to the functionalized plate. The cantilever is then withdrawn from the surface of the Petri dish to measure the cell mass over time. d, DIC image showing the top view of the L-shaped cantilever shown in $\mathbf{a}$ and $\mathbf{b}$. The image of the HeLa cell attached to the plate at the end of the cantilever was recorded while measuring its mass. e, f, Mass over time (black curve) obtained for two HeLa cells, each adhering to the plate at the end of an L-shaped cantilever. Fast (red lines) and slow (green lines) mass fluctuations are identified. Fast fluctuations have an amplitude of $14 \pm 1 \mathrm{pg}$ (mean \pm s.e.; $n=166)$ and a period of 
$1.9 \pm 0.1 \mathrm{~s}$; slow fluctuations have an amplitude of $15 \pm 3 \mathrm{pg}(n=13)$ and a period of $17.3 \pm 1.6$ s. Values are means [Author: Correct?] obtained from the identified extremes (peaks and valleys) (Extended Data Fig. 3). The values are within the margin of error of data obtained using ordinary microcantilevers (Fig. 2). $n$ is the number of fluctuations analysed from at least three biologically independent cells. Scale bars, $10 \mu \mathrm{m}$.

\section{Figure 4 | Infection with vaccinia virus (VACV) stops growth of animal cells. a,} Schematic of directed single cell-to-cell VACV infection. An uninfected HeLa cell, which has spread on the microcantilever, is held for about $5 \mathrm{~min}$ in contact with a VACV-infected BSC40 cell. b, Overlaid DIC and fluorescent images acquired during the controlled cell-cell contact step of infection. c, Overlaid DIC and fluorescence images recorded simultaneously with the mass measurements shown in e. Left and right columns correspond to uninfected and VACV-infected HeLa cells, respectively. Green shows eGFP-tagged VACV, which becomes more numerous with virus production. After being cultured on the cantilever for $8 \mathrm{~h}$ the uninfected cell rounds for mitosis. d, Mass fluctuations of three different VACV-infected HeLa cells at $10 \mathrm{~ms}$ time resolution. Infected HeLa cells experience fast mass fluctuations (red lines; period, $1.9 \pm 0.1 \mathrm{~s}$; amplitude $15 \pm 1 \mathrm{pg}$ (ave \pm s.e.; $n=402)$ ) and slow mass fluctuations (green lines; period $17.0 \pm 1.5 \mathrm{~s}$; amplitude $15 \pm 2 \mathrm{pg}(n=31)$ ) (additional data shown in Extended Data Fig. 8). $n$ is the number of fluctuations analysed from at least three biologically independent cells. e, Long-term mass measurements of uninfected (black line) and VACV-infected (red line) HeLa cells (additional data shown in Extended Data Fig. 2). The mass of the infected cell remains roughly constant (no cell growth) while producing viruses (additional data shown in Extended Data Fig. 9). The uninfected HeLa cell grows and divides several times. During mitosis, the cells partially de-adhere from the cantilever and re-adhere after anaphase, inducing the observed dips. Scale bars, $20 \mu \mathrm{m}$.

\section{METHODS}

\section{Cell lines}

Mouse fibroblasts stably expressing H2B-eGFP and mCherry-actin were created by subcloning sequences encoding H2B-eGFP and mCherry-actin into the lentiviral vector (pRRLSIN.cPPT.PGK.WPRE). Lentiviruses carrying the H2B-eGFP and mCherry-actin transgenes were obtained in the laboratory using a standardized 
$\operatorname{protocol}^{32}$. Mouse fibroblasts were co-transduced with these lentiviruses at an approximate multiplicity of infection of three. After several passages, fluorescenceactivated cell sorting (FACS) was used to select cells stably expressing both H2BeGFP and mCherry-actin. A HeLa cell line stably expressing H2B-eGFP and actinmCherry was provided by A. Hyman. HeLa (ATCC CCL-2) and BSC40 cells (ATCC CRL-2761) were used as viral host cell lines. Every cell line was regularly tested for mycoplasma contamination and was authenticated by the colleague providing the line.

\section{Cell culture}

Cells were cultured in phenol red-free, high-glucose Dulbecco's modified Eagle's medium (DMEM), supplemented with $1 \mathrm{mM}$ sodium pyruvate, $4 \mathrm{mM}$ GlutaMAX and $10 \%(\mathrm{v} / \mathrm{v}) \mathrm{FCS}$. The cell culture medium also contained 100 units $\mathrm{ml}^{-1}$ penicillin and $10 \mu \mathrm{g} \mathrm{ml}^{-1}$ streptomycin (Gibco-Life technologies). Cells were cultured in T-25 flasks at $37{ }^{\circ} \mathrm{C}$ with $5 \% \mathrm{CO}_{2}$ in the atmosphere. Upon reaching a confluency of $70-80 \%$, cells were split. Cells were used for a maximum of 25 passages. T-25 flasks used to culture the mouse fibroblasts were freshly coated $\left(50 \mu \mathrm{g} \mathrm{ml}^{-1}\right)$ with fibronectin (calbiochem).

\section{Cell culture conditions during the experiments}

Long-term measurements (up to several days) were needed to measure the growth behaviour of infected and uninfected cells. Therefore, we engineered a controlled environmental system (CES) that is compatible with the cell balance setup and optical microscopy. It provides culture conditions, as the temperature can be set to $37.0^{\circ} \mathrm{C}$ and the $\mathrm{pH}$ can be controlled by using a humidified gas mixture based on synthetic air containing 5\% $\mathrm{CO}_{2}$. The CES consists of two concentric chambers. The inner chamber contains the Petri dish. The surrounding chamber is continuously filled with the humidified gas mixture to regulate the atmosphere within the inner chamber, preventing evaporation of the cell culture medium. Sliding lids surrounding the cantilever holder are used to cover both chambers. The lids allow free movement of the cantilever holder relative to the Petri dish in order to locate and manipulate the desired cell. The CES enabled us to use cell culture medium without the addition of organic buffers such as HEPES, which is known to modify biological functions such as ion channel conductance ${ }^{33}$ and molecule uptake ${ }^{34}$. Phototoxic effects of HEPES have also been reported ${ }^{35}$. 


\section{Mass fluctuation and interphase mass measurements}

For mass measurements, Petri dishes (Ibidi-IbiTreat) were used. Cells grown in T-25 flasks were trypsinized, seeded into a Petri dish filled with $1 \mathrm{ml}$ cell culture medium and located in the CES. The cantilever was functionalized with fibronectin to adhere fibroblasts or collagen type I (PureCol) to adhere HeLa cells. The cantilever was brought into contact with the target cell for 5-10 s, which was sufficient to attach the cell to the cantilever. Afterwards, cantilever and cell were vertically separated by at least $150 \mu \mathrm{m}$ from the dish. This vertical distance was large enough to completely detach the cell from the Petri dish ${ }^{22}$ and to avoid hydrodynamic coupling of the cantilever with the bottom of the dish ${ }^{36}$.

\section{Virus infection measurements}

BSC40 cells were cultured in Petri dishes for one day. At the point of virus infection, the culture had about 20,000 cells. For this study, a recombinant vaccinia virus (western reserve strain) containing an eGFP-tagged version of the core protein A4 in which the F11L gene had been replaced with mCherry was used. Cells were infected at a multiplicity of infection of 0.8 in a volume of $500 \mu 1$ medium without serum. After incubating the cells with VACV for $1 \mathrm{~h}$, the medium was removed and $1 \mathrm{ml}$ normal cell culture medium added. After two days, plaques of VACV-infected BSC40 cells were observed by fluorescence microscopy. The majority of BSC40 cells remained uninfected. The dish was washed and new medium with serum was added before insertion into the CES of the cell balance. HeLa cells were trypsinized, added to the dish and picked up using collagen type I functionalized cantilevers. After the HeLa cell had spread on the cantilever it was brought into contact with a VACVinfected BSC40 cell for 5 min by moving the stepper actuators of the cell balance in $1-\mu \mathrm{m}$ increments. To increase the chance of infection, the HeLa cell was brought into contact with three other infected BSC40 cells, for 5 min each. We used BSC40 cells instead of HeLa to infect HeLa cells because BSC40 cells establish lower cell-cell adhesion. Thus, even after a contact time of $5 \mathrm{~min}, \mathrm{BSC} 40$ and HeLa cells could be separated without morphological distortion. After the last cell-to-cell contact, the cantilever was lifted up by at least $150 \mu \mathrm{m}$ and the HeLa cell was allowed to recover for $1-2 \mathrm{~h}$ before mass measurements were started. 


\section{Cantilever production, calibration, cleanliness and functionalization}

Two types of customized tipless silicon cantilever were used for the experiments with animal cells. The dimension of the first type of cantilever used for short-term measurements (tens of seconds) was $75 \times 30 \times 1 \mu \mathrm{m}^{3}$. These cantilevers were milled from ARROW ${ }^{\mathrm{TM}}$ TL8 cantilevers (Nanoworld) using a focused ion beam (FIB). The second type of cantilever was designed for long-term measurements (days) and had dimensions of approximately $135 \times 40 \times 2 \mu \mathrm{m}^{3}$. These cantilevers had a larger surface to provide sufficient space to host several cell generations in the case of dividing cells. The cantilevers were FIB-milled from ACST-TL Soft Tip-less cantilevers (AppNano), OMCL-AC240TN (Olympus) and NSC35 (Mikromasch). To show the working principle of mass detection, NANOSENSORS ${ }^{\mathrm{TM}}$ TL-NCH cantilevers were FIB-milled to have silicon blocks (balancing weights) at different locations (Fig. 1d and Extended Data Fig. 1). The silicon blocks were later removed using FIB. Lshaped cantilevers insensitive to cell movements were FIB-milled from NANOSENSORS ${ }^{\mathrm{TM}}$ TL-NCL cantilevers (Fig. 3).

For functionalization, cantilevers were cleaned in 95\% sulfuric acid for $3 \mathrm{~min}$ at room temperature. During this time, the cantilevers were gently moved manually in the acid. After this step, the cantilevers were rinsed three times with ultrapure water (approximately $18 \mathrm{MOhm} \mathrm{cm}^{-1}$ ) and dried with precision wipes (Kimtech Science). Then, the cantilevers were placed for $15 \mathrm{~min}$ in a UVO cleaner (Jelight Company Inc.). After UVO treatment, the cantilevers were incubated in $50.0 \mathrm{mg} \mathrm{ml}^{-1}$ fibronectin (Calbiochem) or $3.1 \mathrm{mg} \mathrm{ml}^{-1}$ collagen type I (PureCol) for $1 \mathrm{~h}$ at $37^{\circ} \mathrm{C}^{21,22}$. Subsequently the cantilevers were rinsed with PBS solution and immediately used to attach cells. Cantilever spring constants were determined using the Sader method ${ }^{37}$ or by pressing the cantilever against a reference cantilever.

\section{Coulter counter and sizer}

To measure the average diameters of mouse fibroblasts and HeLa cells, a Beckman Coulter Z2 (Beckman Coulter Inc.) with an aperture of $100 \mu \mathrm{m}$ was used. The counting range was set from 8 to $24 \mu \mathrm{m}$. Within this range a background of three counts per $0.5 \mathrm{ml}$ electrolyte solution (Isoton II, Beckman Coulter) was measured. After flushing the system, a cuvette containing $10 \mathrm{ml}$ electrolyte solution and $0.1 \mathrm{ml}$ suspended cells in medium (around $1.2 \times 10^{5}$ cells ml$^{-1}$ ) was inserted into the instrument. All cells within a volume of $0.1 \mathrm{ml}$ were characterized. 


\section{System setup}

The setup of the picoscopic cell balance (Extended Data Fig. 10) includes two customized $405 \mathrm{~nm}$ and $852 \mathrm{~nm}$ lasers manufactured by Schäfter + Kirchhoff GmbH. The $405 \mathrm{~nm}$ laser was driven in current control mode by a laser diode controller (LDC500, Stanford Research Systems). To improve the laser stability, the $405 \mathrm{~nm}$ laser diode temperature was kept constant using a Peltier element, which was controlled by a thermoelectric controller (LDC500). A four-quadrant Si PIN photodiode (S5980 Hamamatsu) measured the deflection of the cantilever by the $852 \mathrm{~nm}$ laser. To prevent any other radiation from reaching the photodiode, a hardcoated bandpass filter (Edmund Optics) with a centred wavelength of $850 \mathrm{~nm}, 25 \mathrm{~nm}$ bandwidth and optical density of 4 was located in front of the photodiode. The amplitude and phase of the cantilever oscillations were measured using a lock-in amplifier. The resonance frequency of the cantilever was tracked by a phase-locked loop (PLL), which commanded a function generator to modulate the intensity of the $405 \mathrm{~nm}$ laser. Two different lock-in amplifiers and PLLs were used, a Nanonis device (comprising a BP4.5 control system and an OC4 oscillation controller) and a modified C3000 controller from Nanosurf AG.

\section{Statistical analysis}

Two-tailed student's $t$-tests were applied to determine significant differences between the mean fluctuation amplitudes and periods. The amplitude of the mass fluctuations for each regime (fast or slow) was calculated by the mass difference between two adjacent extrema divided by two. The time period was calculated from the time difference between adjacent mass peaks and valleys (mass extrema) multiplied by two. The null hypothesis for the tests was mean $_{\text {Control }}-$ mean $_{\text {Perturbation }}=0$. Differences were considered not significant (NS) if $P>0.05$, and significance indicated as follows: $* P \leq 0.05, * * P \leq 0.01, * * * P \leq 0.001$ and $* * * * P \leq 0.0001$. To indicate the strength of the significant effect, confidence intervals for the difference of the means were provided for a confidence level of $95 \%$. All tests were done using OriginPro 8.6 (OriginLab Cooperation).

\section{Data availability}

The data that support the findings of this study are available from the corresponding authors upon reasonable request. 


\section{Code availability}

The custom code for identifying the position of the cell on the cantilever is available from the authors upon reasonable request.

$<$ unknown $>32$. Barde, I., Salmon, P. \& Trono, D. Production and titration of lentiviral vector. Curr. Protoc. Neurosci. 53, 4.21 .21 (2010). </unknown>

$<$ jrn $>33$. Hanrahan, J. W. \& Tabcharani, J. A. Inhibition of an outwardly rectifying anion channel by HEPES and related buffers. J. Membr. Biol. 116, 65-77 (1990). Medline CrossRef $</$ jrn $>$

<jrn>34. $\quad$ Otero, D. H., Wilbekin, F. \& Meyer, E. M. Effects of 4-(2hydroxyethyl)-1-piperazine-ethanesulfonic acid (AH5183) on rat cortical synaptosome choline uptake, acetylcholine storage and release. Brain Res. 359, 208-214 (1985). Medline $\underline{\text { CrossRef }</ j r n>}$

$<$ jrn $>35$. Lepe-Zuniga, J. L., Zigler, J. S., Jr \& Gery, I. Toxicity of light-exposed Hepes media. J. Immunol. Methods 103, 145 (1987). Medline CrossRef</jrn>

$<$ jrn $>36 . \quad$ Green, C. P. \& Sader, J. E. Frequency response of cantilever beams immersed in viscous fluids near a solid surface with applications to the atomic force microscope. J. Appl. Phys. 98, 114913 (2005). CrossRef $</$ jrn>

$<$ jrn>37. Sader, J. E., Chon, J. W. M. \& Mulvaney, P. Calibration of rectangular atomic force microscope cantilevers. Rev. Sci. Instrum. 70, 3967-3969 (1999). $\underline{\text { CrossRef }</ j r n>}$

$<\mathrm{jrn}>38$. Lyamzaev, K. G. et al. Inhibition of mitochondrial bioenergetics: the effects on structure of mitochondria in the cell and on apoptosis. Acta Biochim. Pol. 51, 553-562 (2004). Medline $<$ jrn $>$

$<$ jrn>39. Domenis, R., Bisetto, E., Rossi, D., Comelli, M. \& Mavelli, I. Glucose-modulated mitochondria adaptation in tumor cells: a focus on ATP synthase and inhibitor Factor 1. Int. J. Mol. Sci. 13, 1933-1950 (2012). $\underline{\text { Medline }} \underline{\text { CrossRef }}</$ jrn $>$

$<\mathrm{jrn}>40$. Hosios, A. M. et al. Amino acids rather than glucose account for the majority of cell mass in proliferating mammalian cells. Dev. Cell 36, 540-549 (2016). Medline $\underline{\text { CrossRef }</ j r n>}$ 
$<$ jrn $>$ 41. Savage, D. F. \& Stroud, R. M. Structural basis of aquaporin inhibition by mercury. J. Mol. Biol. 368, 607-617 (2007). Medline CrossRef $</$ jrn $>$

[Author: Please ensure that the following information is included in the figure legends where relevant. Sample size (exact $n$ number); a statement of replicability (how many times was experiment replicated in the laboratory); description of sample collection (clarify whether technical or biological replicates and include how many animals, litters, cultures, etc.); state the statistical test used and give $P$ values; define centre values (median or average) and error bars. For figures/images that are reproduced or adapted from a third party, it is important that you confirm that permission has been obtained and that appropriate acknowledgement of the copyright holder is given.]

\section{Extended Data Figure 1 | Control mass measurement operating the picobalance}

in cell culture conditions. a-e, Side and top view SEM images of an FIBmanufactured microcantilever with and without a weight sculpted from a silicon block. Theoretically, the mass sensitivity of the cantilever is highest if the mass is added to the free end of the cantilever and lowest (that is, zero) if the mass is added to the fixed end (Supplementary Note 3 ). To experimentally evaluate the mass sensitivity of the cantilever as a function of the location of the added mass, the weight is shifted by $10 \mu \mathrm{m}$ from the free end of the cantilever. From the dimensions of the silicon block $\left(10.1 \times 21.2 \times 1.8 \mu^{3}\right)$ a mass of $0.90 \pm 0.12 \mathrm{ng}$ (value \pm propagated error) is calculated using the density of silicon $\left(2.33 \mathrm{~g} \mathrm{~cm}^{-3}\right)$. After removal of the block by FIB milling, SEM shows a residual volume of $0.9 \times 21.2 \times 1.8 \mu^{3}$, which corresponds to a mass $m_{\text {residual }} \approx 0.08 \pm 0.01 \mathrm{ng}$. Therefore, a mass of $0.90-0.08=0.82 \pm 0.12 \mathrm{ng}$ is expected to be added by the silicon block. f, Phase curves recorded in cell culture medium for the cantilever with (b) and without (c) the silicon block. The natural resonance frequency of the cantilever (arrows) increases by $4.542 \mathrm{kHz}$ after the block is removed. Taking into account the position of the block on the cantilever, this frequency shift accounts for a mass difference of $0.81 \pm 0.02 \mathrm{ng}$, which is in good agreement with the mass expected from volume measurements by SEM. Thin solid lines on top of the experimental data in $\mathbf{f}$ correspond to fittings of a driven and damped harmonic oscillator. Equations used for the fit are introduced in Supplementary Note 2 . The measurements are complementary to the control mass measurements shown in Fig. 1d, e. Scale bars, $20 \mu \mathrm{m}(\mathbf{a}), 5 \mu \mathrm{m}(\mathbf{b}, \mathbf{c})$ and $10 \mu \mathrm{m}(\mathbf{d}$, e). 


\section{Extended Data Figure 2 | The controlled environmental system provides culture} conditions for mammalian cells adhering to the substrate-coated

microcantilever. a, MDCK II cells adhering to a collagen type I functionalized cantilever $^{20,21}$ in culture medium. Culture conditions are provided by the controlled environmental system of the balance (Fig. 1a). Shown are superimposed DIC and fluorescence images recorded at the times indicated by time stamps at the bottom of each image. Time stamps correspond to hours:minutes. The time-lapse images show that the cells progress through multiple cell cycles and remain alive and viable for several days until the mass measurement (the mass measured is shown in other examples) is terminated. Cells were cultured in phenol red-free, high-glucose DMEM, supplemented with $1 \mathrm{mM}$ sodium pyruvate, $4 \mathrm{mM}$ GlutaMAX, 10\% (v/v) FCS, 100 units $\mathrm{ml}^{-1}$ penicillin and $10 \mu \mathrm{g} \mathrm{ml}^{-1}$ streptomycin. Scale bar, $20 \mu \mathrm{m}$. The MDCK II cell line stably expressing H2B-eGFP was created by subcloning sequences encoding H2B-eGFP into a lentiviral vector (pRRLsincPPT-PGK.WPRE) using a standardized protocol ${ }^{32}$. Lentiviruses carrying the H2B-eGFP transgenes were obtained in our laboratory and used to transduce MDCK cells (clone II, provided by B. Roska). FACS was used to select cells stably expressing H2B-eGFP. b, Mass measurement acquired simultaneously with $\mathbf{a}$. In mitosis, cells detach partially from the cantilever and reattach after anaphase, producing the dips observed in the measurements. Dashed lines (red) and time stamps mark the first three dividing cells, which can be seen in a. Owing to the lack of space to accommodate the growing number of cells, some cells migrate towards the fixed end of the cantilever after about $48 \mathrm{~h}$. For this reason, the mass measurement was stopped. Long-term experiments such as these were conducted at least ten times with biologically independent cells.

\section{Extended Data Figure 3 | Mass fluctuation analysis of single fibroblasts and}

HeLa cells. a, Schematic demonstrating the decomposition into two oscillations that result in mass fluctuations. The fluctuation shown on the left (black line) is composed of two oscillations differing in period (fast and slow) and amplitude (fast and slow mass extrema). The fast oscillation has a period $t_{\text {fast }}$ and amplitude $A_{\text {fast}}$, the slow oscillation has a period $t_{\text {slow }}$ and amplitude $A_{\text {slow }}$. b, Analysing the fast and slow components of experimentally determined cell mass fluctuations. The top row shows fibroblasts (data from Fig. 2c) and the bottom row HeLa cells (data from Fig. 2d). Black lines represent the cell mass recorded over time. The faster mass fluctuations 
(red line) overlapping the slower mass fluctuations (green line) are obtained by smoothing the cell mass over time. Orange and blue dots show extremes (peaks and valleys) of the faster and slower mass fluctuations, respectively. The data analysis reveals that fibroblasts experience fast mass fluctuations (red lines) with period $2.2 \pm 0.1 \mathrm{~s}$ and amplitude $14 \pm 1 \mathrm{pg}$ (mean \pm s.e.; $n=132)$ and slow mass fluctuations (green lines) with period 17.6 $\pm 2.0 \mathrm{~s}$ and amplitude $12 \pm 1 \mathrm{pg}(n=10)$. HeLa cells experience fast mass fluctuations with period $2.1 \pm 0.1 \mathrm{~s}$ and amplitude $15 \pm 1 \mathrm{pg}$ $(n=177)$ and slow mass fluctuations with period $18.0 \pm 1.4 \mathrm{~s}$ and amplitude $14 \pm 2 \mathrm{pg}$ $(n=17)$. The average amplitude of the mass fluctuations for each regime (fast or slow) is calculated by the mass difference between two adjacent extrema divided by two. The average time period is calculated from the time difference between adjacent mass peaks and valleys (mass extrema) multiplied by two. $n$ is the number of fluctuations analysed from at least three biologically independent cells per cell line.

\section{Extended Data Figure 4 | Time-lapse microscopy of single spread and unspread}

HeLa cells, from which mass fluctuations are characterized. a, Time-lapse DIC images correspond to the HeLa cell from which mass was measured in Fig. 2d (right). Images at higher magnification are presented below. b, Time-lapse DIC images corresponding to the VACV-infected HeLa cell from which mass was measured in Fig. $4 \mathrm{~d}$ (right). The first DIC image of the time-lapse experiment shows an overlaid fluorescent channel confirming that the cell was infected with VACV. The fluorescence signal of the eGFP-tagged VACV is shown in green. Images of the VACV-infected cell are presented at higher magnification below. In neither experiment did the cells observably change position on the cantilever. c, Time-lapse of a HeLa cell freshly attached to a microcantilever. The rounded cell is not yet spread, which prevents the cell from migrating. The cell is fluorescently labelled with CellTracker Green CMFDA (cytoplasmic dye) and NucBlue (nuclear dye). DIC and fluorescent images are recorded every $10 \mathrm{~s}$. Upper and lower rows show DIC images overlapped with cytoplasmic (green) and nuclear (blue) fluorescent channels, respectively. No movement of the cell or nucleus is detected within the optical resolution limit. d, Mass fluctuations of two different unspread HeLa cells adhering to a microcantilever. The mass curve on the left corresponds to the cell shown in $\mathbf{c}$ and was recorded simultaneously with the images in c. The fast fluctuations (red lines) have an amplitude of $15 \pm 1 \mathrm{pg}($ mean \pm s.e.; $n=129)$ with a period of $1.9 \pm 0.1 \mathrm{~s}$ 
while the slow fluctuations (green lines) have an amplitude of $16 \pm 2 \mathrm{pg}(n=10)$ with a period of $19.0 \pm 1.2 \mathrm{~s}$. Values are means obtained from the identified extremes (peaks and valleys), which are marked with orange and blue dots for the fast and slow fluctuations, respectively. $n$ is the number of fluctuations analysed from at least three biologically independent cells. e, To generate fast mass fluctuations (30 pg from amplitude peak to peak; Fig. 2), a cell adhering to the microcantilever would need to change position along the long cantilever axis by around $0.6 \mu \mathrm{m}$ with a frequency of around $0.5 \mathrm{~Hz}$ (Supplementary Note 4). Such fast movements have not been reported so far, nor were they observed in our experiments by monitoring the cell morphology over time. The cantilever used in the experiment in $\mathbf{c}$ had a length of $135 \mu \mathrm{m}$. Scale bars $20 \mu \mathrm{m}(\mathbf{a}, \mathbf{b}), 10 \mu \mathrm{m}$ (c).

\section{Extended Data Figure 5 | Cell adhesion and spreading do not affect the} cantilever spring constant. a, Force-displacement curves recorded using a cantilever with and without an adherent mouse fibroblast. To record force-displacement curves, a cantilever used for mass measurements is pressed against a calibrated reference cantilever. The system, which behaves as two springs in series, determines whether the presence of an adherent cell changes the spring constant of the cantilever. $\mathbf{b}$, Optical microscopy image showing the cantilever used for mass measurements (right) pushed against a reference cantilever (left). $\mathbf{c}-\mathbf{e}$, Cantilevers with an adherent fibroblast used for mass measurements. Overlaid DIC and fluorescence images of mCherry-actin (red) and H2B-eGFP (green) show the fibroblast in different spread states. The slopes of the force-displacement curves in a reveal the effective spring constant $k_{\text {eff }}$ of the coupled spring system. As the slopes of the force curves do not change with the presence and spreading of the fibroblast, we conclude that the cantilever spring constant remains unaffected by the fibroblast. Measurements were made using a commercial AFM (CellHesion 200, JPK Instruments) under cell culture conditions. The reference cantilever (Olympus OMCL-RC) had dimensions of $100 \times 40 \times 0.8 \mu \mathrm{m}^{3}$ and a spring constant of $0.65 \mathrm{~N} \mathrm{~m}^{-1}$. The cantilever used for mass measurements had dimensions of $76.3 \times 30.0 \times 1.0 \mu \mathrm{m}^{3}$ and a spring constant of $1.85 \mathrm{~N} \mathrm{~m}^{-1}$. The experiment was repeated at least three times with biologically independent cells.

Extended Data Figure 6 | Cantilever bending induced by a contracting adherent mammalian cell shows no influence on cell mass measurement. a, Deflection of 
the cantilever with an adherent fibroblast. During the measurement, the fibroblast contracted, causing mechanical stress, and deflected the cantilever. b, Mass of the fibroblast recorded simultaneously with $\mathbf{a}$. The lack of correlation between $\mathbf{a}$ and $\mathbf{b}$ demonstrates that the deflections of the cantilever do not affect the mass measurement. The FIB-manufactured cantilever had dimensions of $75.5 \times 27.9 \times$ $1.0 \mu^{3}$ and a spring constant of $1.86 \mathrm{~N} \mathrm{~m}^{-1}$. Measurements were made under cell culture conditions. The medium was high-glucose DMEM with phenol red, supplemented with $1 \mathrm{mM}$ sodium pyruvate, $4 \mathrm{mM}$ GlutaMAX and 10\% (v/v) FCS. The medium also contained 100 units per ml penicillin and $10 \mu \mathrm{g} \mathrm{ml}^{-1}$ streptomycin (Gibco-Life technologies). The experiment was repeated at least three times with biologically independent cells.

\section{Extended Data Figure 7 | Mass fluctuations of HeLa cells depend on water} transport and ATP synthesis. Shown are perturbation experiments correlating the observed fast and slow mass fluctuations with biological processes. Each curve corresponds to a single HeLa cell. Every experimental condition was repeated at least three times using different cells. The numerical and statistical analysis of the fluctuations for each condition is shown in Table 1. a, Mass fluctuations of a single HeLa cell under cell culture conditions (data from Fig. 2) as a control. b, HeLa cell under the effect of 2,4-dinitrophenol, which lowers ATP production by dissipating the proton gradient in mitochondria ${ }^{38}$. No significant changes were detected with respect to the control. 2,4-dinitrophenol was added $1 \mathrm{~h}$ before the measurements. c, HeLa cell perturbed with oligomycin A, which inhibits ATP synthase ${ }^{39}$. The mass fluctuations observed were similar to the control. Oligomycin A was added 30 min before the measurements ${ }^{40}$. d, HeLa cell cultured in glucose-free culture medium (Methods). Prior to the mass measurements the cells were cultured in glucose-free medium for $12 \mathrm{~h}$ to prevent glycolysis. However, other sources of energy such as glutamine were accessible for the cells ${ }^{40}$. No significant changes in the mass fluctuations were observed, see Table 1. e, HeLa cell perturbed with oligomycin A as in c but cultured in glucose-free medium as in $\mathbf{d}$ to more efficiently deplete the energy of the cell. Significant changes were observed in the amplitudes of the slow and fast mass fluctuations, which decreased by around $79 \%$ and $33 \%$, respectively (Table 1). f, HeLa cell under the effect of mercury(II) chloride, which blocks aquaporins from 
transporting water ${ }^{41}$. Compared to the control cells, the amplitudes of the slow and fast mass fluctuations decreased by around $71 \%$ and $27 \%$, respectively.

Extended Data Figure 8 | Mass fluctuations of VACV-infected HeLa cells. Each graph corresponds to a different VACV-infected HeLa cell. Black lines depict the cell mass recorded with a time resolution of $10 \mathrm{~ms}$. VACV-infected HeLa cells show fast mass fluctuations (red lines) with a period of $1.9 \pm 0.1 \mathrm{~s}($ mean \pm s.e.; $n=402)$ and an amplitude of $15 \pm 1 \mathrm{pg}$ and slow mass fluctuations (green lines) with a period of $17.0 \pm 1.5 \mathrm{~s}(n=31)$ and an amplitude of $15 \pm 2 \mathrm{pg} . n$ is the number of fluctuations analysed from at least ten biologically independent cells. Single cell mass measurements include those shown in the main manuscript.

\section{Extended Data Figure 9 | Long-term mass measurements of single VACV-}

infected and uninfected HeLa cells. The red curve shows the growth and proliferation of an uninfected HeLa cell adhering to a microcantilever. After about $9 \mathrm{~h}$, the cell progresses through mitosis and the two daughter cells keep growing. Black curves show the mass of single HeLa cells that have been infected with VACV. Superimposed DIC and fluorescence images show the HeLa cells at the beginning of the experiment and after several hours. The green fluorescence signal indicates the presence of eGFP-tagged VACV as a result of virus production. The mass of VACVinfected HeLa cells remains largely unchanged during virus production. The experiment with virus-infected cells was repeated ten times with biologically independent cells. Additional data are shown in Fig. 4.

Extended Data Figure 10 | Setup and block diagram of the picobalance. The intensity-modulated blue laser excites an oscillatory movement of the microcantilever, which is detected by an infrared laser (red) reflected from the free cantilever end onto a four-quadrant photodiode. To measure the amplitude and phase of the cantilever movement the signal from the photodiode is analysed by a lock-in amplifier. For high time resolution measurements, a phase-locked loop instantaneously tracks the natural resonance frequency of the cantilever. 


\section{FIGURES AND LEGENDS}

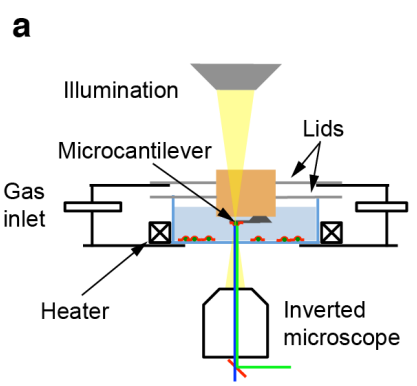

d



b

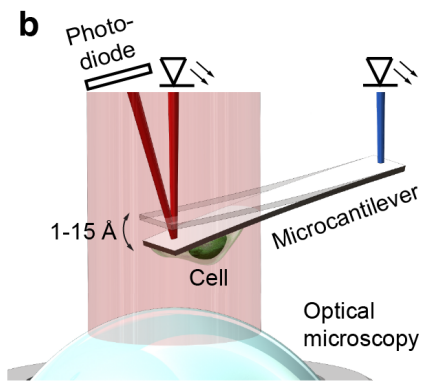

e

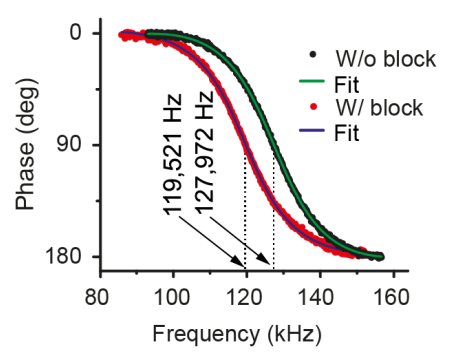

c



f



Figure 1 | Working principle of the picoscopic cell balance in culture conditions. a, Design of the cell balance. The chamber surrounding the microcantilever used to pick up and measure the mass of an adherent cell controls temperature, gas atmosphere and humidity to prevent evaporation of the culture medium (Methods). Sliding lids allow moving the microcantilever holder relative to the Petri dish. The chamber is fully compatible with optical microscopy. $\mathbf{b}$, The mass of a cell adhering to the cantilever is measured by oscillating the cantilever at its natural resonance frequency $f_{\mathrm{N}}$ and very small amplitudes of $\approx 1-15 \AA$. While the cantilever is activated to oscillate via an intensity modulated blue laser at its base, cantilever amplitude and frequency are read out via reflecting an infrared laser from its free end. Simultaneously cell morphology and state are characterized by optical microscopy. c, Typical cantilever amplitude (green) and phase (red) response measured in cell culture medium. A driven and damped harmonic oscillator model fits (thin lines) the experimental data. $f_{\mathrm{N}}$ is the cantilever frequency at a phase of $90^{\circ}$. $\mathrm{d}$, Scanning electron microscopy (SEM) images of a cantilever with and without a weight at the end. The weight $\left(11.6 \times 25.8 \times 2.5 \mu \mathrm{m}^{3}, \mathrm{~L} \times \mathrm{W} \times \mathrm{T}\right)$ made of silicon $\left(2.33 \mathrm{~g} \mathrm{~cm}^{-3}\right)$ has a mass of $1.74 \pm 0.23 \mathrm{ng}$. Scale bars, $15 \mu \mathrm{m}$ (left) and $5 \mu \mathrm{m}$ (right). e, Phase curves of the cantilever with and without the balancing weight (shown in c) as measured in culture medium. The shift of $f_{\mathrm{N}}$ by $8.451 \mathrm{kHz}$ corresponds to a mass of $1.61 \mathrm{ng}$. $\mathbf{f}$, Noise of the $f_{\mathrm{N}}$ of a cantilever in culture medium. The data recorded over two hours shows the high stability of the balance and its sensitivity in the picogram $\left(10^{-12} \mathrm{~g}\right)$ range. 
a

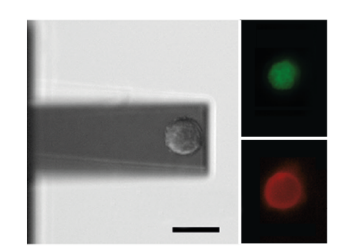

b

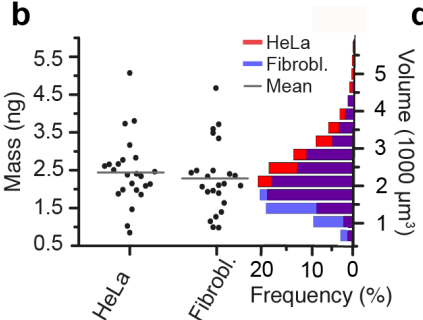

C

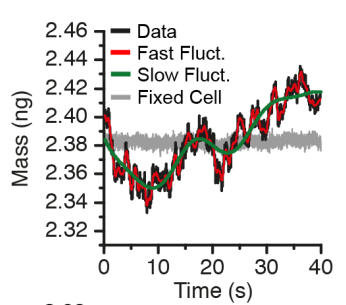

$\left.\begin{array}{l}2.08 \\ 2.06\end{array}\right]$

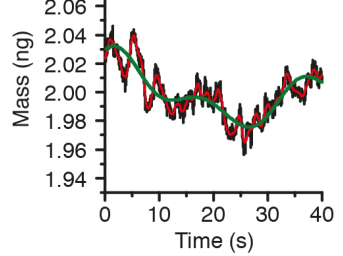

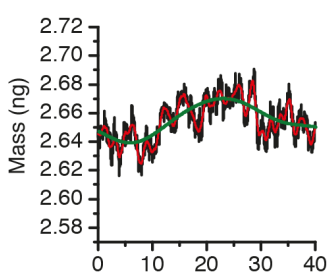
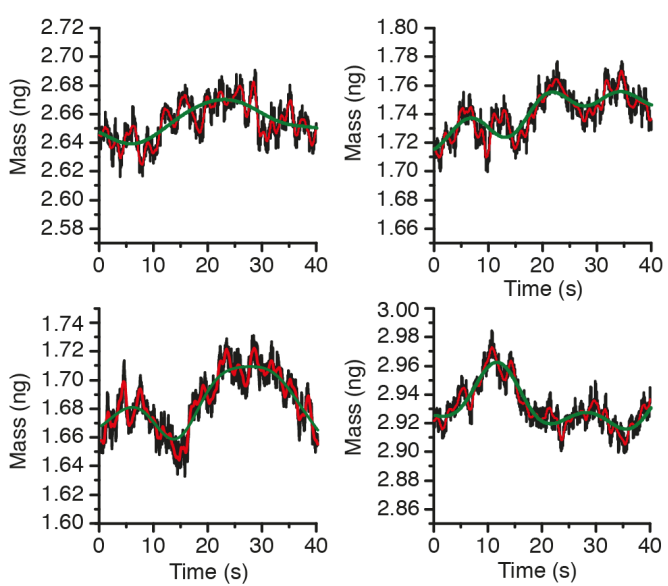

Figure 2 | Mass fluctuations of single adherent animal cells in interphase. a, DIC and fluorescent images of a rounded interphase fibroblast attached to a collagen-coated microcantilever. eGFP labelled histone (H2B-eGFP, green) and mCherry labelled actin (mCherry-actin, red) are visualized. $\mathbf{b}$, Interphase cell mass measured for single HeLa cells and fibroblasts (left side of the chart). Each dot corresponds to the mass of a single cell. The average mass (grey lines) of HeLa cells was $2.43 \pm 0.19 \mathrm{ng}$ (ave \pm s.e.; $n=24$ ) and of fibroblasts was $2.29 \pm 0.19 \mathrm{ng}(n=24)$. The volume distribution of interphase HeLa cells and fibroblasts as acquired with a Coulter device is on the right side of the chart. Volumes of $2310 \pm 55 \mu \mathrm{m}^{3}$ (ave \pm s.e.; $n=606$ ) and $2003 \pm 59 \mu \mathrm{m}^{3}(n=612$ ) were obtained for HeLa cells and fibroblasts, respectively. $\mathbf{c}$ and $\mathbf{d}$, Mass of $\mathbf{c}$ three different fibroblasts and $\mathbf{d}$ three different HeLa cells monitored at $10 \mathrm{~ms}$ time resolution (black lines). Fibroblasts experience mass fluctuations of a fast time period (red lines) of $2.2 \pm 0.1 \mathrm{~s}$ (ave \pm s.e.; $n=105$ ) with $14 \pm 1 \mathrm{pg}$ (ave \pm s.e.) amplitude and of a slow time period (green lines) of $16.2 \pm 2.3 \mathrm{~s}(n=8)$ with $13 \pm 2 \mathrm{pg}$ amplitude. HeLa cells experience mass fluctuations of a fast time period of $2.1 \pm 0.1 \mathrm{~s}(n=177)$ with $15 \pm 1 \mathrm{pg}$ amplitude and of a slow time period of $18.0 \pm 1.4 \mathrm{~s}$ $(n=10)$ with $14 \pm 2 \mathrm{pg}$. For details of analysis see Extended Data Fig. 3. The first graph in c also shows the mass over time of a chemically fixed fibroblast (grey line), which has been offset to facilitate comparison. Scale bar, $20 \mu \mathrm{m}$. 


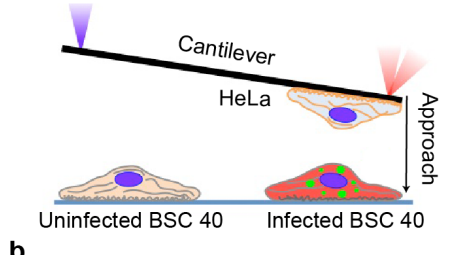

b



d

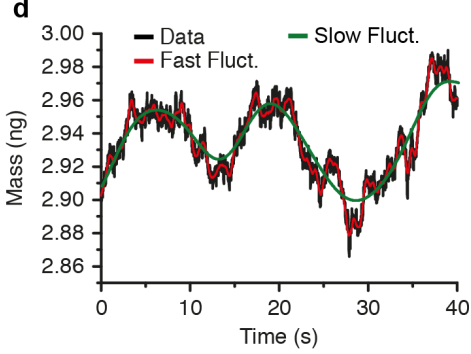

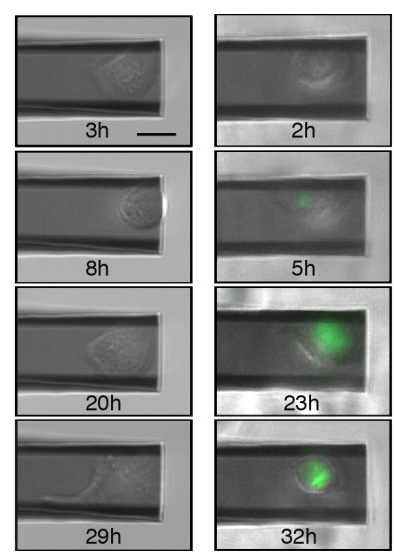

$32 \mathrm{~h}$

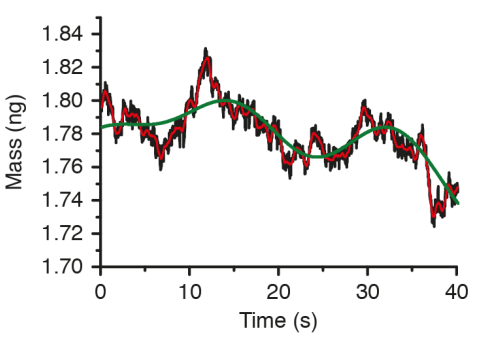

e
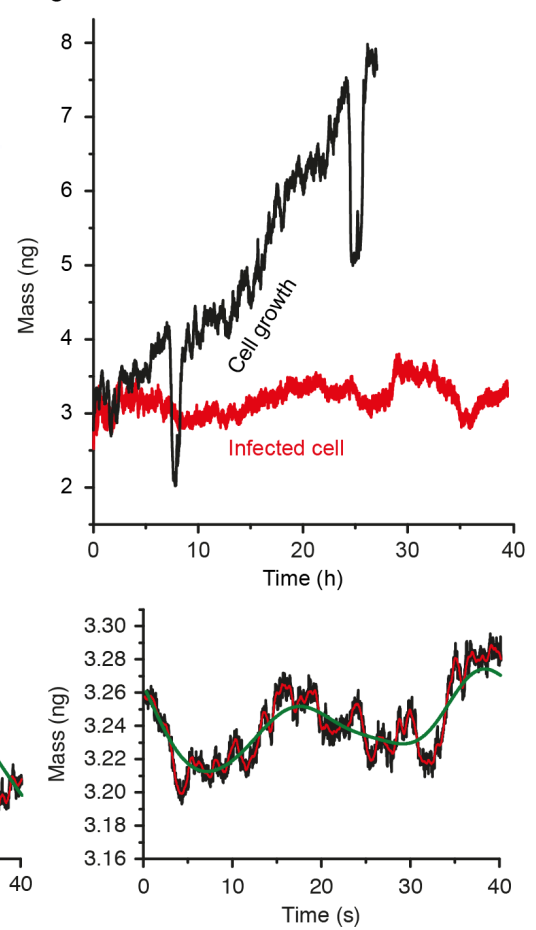

Figure 3 | Infection with the vaccinia virus (VACV) stops growth of animal cells. a, Schematic of directed single cell-to-cell VACV infection. An uninfected HeLa cell, which has spread on the microcantilever, is held for $\approx 5 \mathrm{~min}$ in contact with a VACV-infected BSC40 cell. b, Overlaid DIC and fluorescent images acquired during the controlled cell-cell contact step of infection. c, Overlaid DIC and fluorescence images simultaneously recorded with the mass measurements shown in e. Left and right columns correspond to the uninfected and VACVinfected HeLa cells, respectively. The green channel shows the eGFP-tagged VACV, which becomes more numerous with virus production. After being cultured on the cantilever for 8 hours the uninfected cell rounds for mitosis. $d$, Mass fluctuations of three different VACVinfected HeLa cells at $10 \mathrm{~ms}$ time resolution. Infected HeLa cells experience mass fluctuations with a fast time period (red lines) of $1.9 \pm 0.1 \mathrm{~s}$ (ave \pm s.e.; $n=402$ ) with $15 \pm 1 \mathrm{pg}$ amplitude and a slow time period (green lines) of $17.0 \pm 1.5 \mathrm{~s}(n=31)$ with $15 \pm 2$ pg amplitude (analysis shown in Extended Data Fig. 3 and additional data shown in Extended Data Fig. 10). e, Long term mass measurements of an uninfected (black line) and VACV-infected (red line) HeLa cell (additional data shown in Extended Data Fig. 2). The mass of the infected cell remains roughly constant (no cell growth) while producing viruses (additional data shown in Extended Data Fig. 11). The uninfected HeLa cell grows and divides several times. During mitosis the cells partially de-adhere from the cantilever and readhere after anaphase inducing the dips observed in the measurements. Scale bars, $20 \mu \mathrm{m}$. 